\title{
High-level expression, purification, and enzymatic characterization of truncated human plasminogen (Lys531-Asn791) in the methylotrophic yeast Pichia pastoris
}

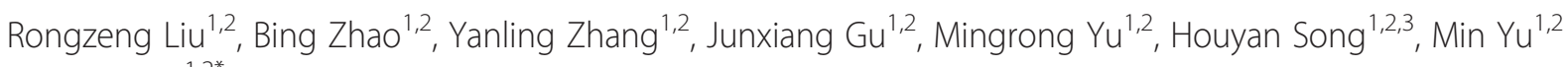
and Wei $\mathrm{Mo}^{1,2^{*}}$

\begin{abstract}
Background: Plasmin is a serine protease that plays a critical role in fibrinolysis, which is a process that prevents blood clots from growing and becoming problematic. Recombinant human microplasminogen (rhuPlg) is a derivative of plasmin that solely consists of the catalytic domain of human plasmin and lacks the five kringle domains found in the native protein. Developing an industrial production method that provides high yields of this protein with high purity, quality, and potency is critical for preclinical research.
\end{abstract}

Results: The human microplasminogen gene was cloned into the pPIC9K vector, and the recombinant plasmid was transformed into Pichia pastoris strain GS115. The concentration of plasmin reached $510.1 \mathrm{mg} / \mathrm{L}$ of culture medium.

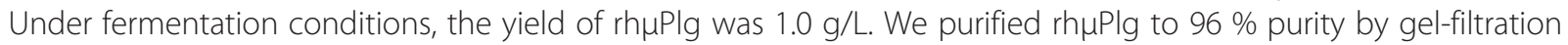
and cation-exchange chromatography. The specific activity of rhuPlg reached $23.6 \mathrm{U} / \mathrm{mg}$. The $K_{m}$ of substrate hydrolysis by recombinant human microplasmin was comparable to that of human plasmin, while rh $\mu$ PIm had higher $k_{\text {cat }} / K m$ values than plasmin. The high purity and activity of the rh $\mu$ Plg obtained here will likely prove to be a valuable tool for studies of its application in thrombotic diseases and vitreoretinopathies.

Conclusions: Reliable rhuPlg production (for use in therapeutic applications) is feasible using genetically modified P. pastoris as a host strain. The successful expression of rh $\mu$ Plg in P. pastoris lays a solid foundation for its downstream application.

Keywords: Truncated plasminogen, Plasmin, Pichia pastoris, Purification, rhuPlg

\section{Background}

Plasminogen, the proenzyme precursor of the primary fibrinolytic protease, plasmin, is a single-chain protein containing of 791 amino acid residues [1]. While plasminogen is expressed in all major organs and tissues, it is synthesized primarily in the liver [2]. Plasminogen is found in significant quantities in extravascular fluids [3]. Circulating plasminogen comprises a Pan-apple (PAp) domain, five kringle domains (KR1-5), and a

\footnotetext{
* Correspondence: weimo1025@shmu.edu.cn

'Key Laboratory of Metabolism and Molecular Medicine, Ministry of Education, Fudan University, 138 Yixueyan Rd, Shanghai 200032, China ${ }^{2}$ Department of Biochemistry and Molecular Biology, School of Basic Medical Sciences, Fudan University, 138 Yixueyan Rd, Shanghai 200032, China Full list of author information is available at the end of the article
}

serine protease (SP) domain [4]. Under physiological conditions, plasminogen is converted to plasmin by a cleavage event that occurs in its activation loop (between Arg561 and Val562), which is facilitated by tissue plasminogen activator (tPA) or urokinase plasminogen activator (uPA). The plasmin molecule is a two-chain, disulfidelinked SP with trypsin-like specificity. The C-terminal light chain of plasmin (residues 562-791, molecular weight (MW) $25 \mathrm{kDa}$ ) contains a typical SP that is homologous to trypsin. The C-terminal light chain also contains the classic catalytic triad, which is composed of His603, Asp646, and Ser741.

Plasmin can undergo an autolytic process, and its cleavage site specificity can change with $\mathrm{pH}$. The specific 
autolytic cleavage of the plasmin molecule in alkaline solutions leads to the formation of a low-molecular-weight form of plasmin, termed microplasmin [5]. Human microplasmin (Lys531-Asn791), which was first prepared from plasmin in an alkaline solution, consists of two polypeptide chains that are connected by disulfide bonds. One polypeptide is the B chain of plasmin that consists of 230 amino acids, while the other peptide is the C-terminal portion of the A chain of plasmin, which consists of 31 amino acid residues [6]. Microplasmin has a molecular weight of $28 \mathrm{kDa}$, as calculated from its primary sequence. It is slightly more positively charged than plasminogen, and it is generally a more hydrophobic molecule [6].

The dissolution of blood clots, whether accomplished physiologically or pharmacologically, is facilitated by plasmin [7]. Plasmin was first studied more than 50 years ago, and it was found to be either ineffective or inferior to plasminogen activators in treating thrombotic diseases [8]. With the current widespread use of catheters to deliver thrombolytic therapy, plasmin has been reevaluated as a potentially valuable thrombolytic agent; pharmacological studies have demonstrated plasmin is an effective and hemostatically-safe application for the treatment of thrombotic diseases [9]. In addition to fibrin, plasmin has been shown to directly degrade other extracellular matrix (ECM) components, including laminin and fibronectin, which have a postulated role in vitreoretinal adhesion [10, 11]. In both enucleated pig and human eyes, the addition of $1 \mathrm{U}$ of plasmin eliminates the cortical vitreous remnants previously detected on the inner limiting membrane, all without the use of adjunctive techniques $[12,13]$.

However, the isolation of autologous plasmin is a costly and time-consuming process. Furthermore, it is difficult to produce plasmin via recombinant gene technology because of its high molecular weight and tendency to degrade [14]. Therefore, the availability of lower molecular weight and more stable microplasminogen $(\mu \mathrm{Plg})$ represents a valuable tool that might be applied to the treatment of thrombotic diseases and vitreoretinopathies (pending preclinical and clinical evaluation). In response to this need, we developed a protocol to produce abundant quantities of highly active and high-purity rh $\mu \mathrm{Plg}$ (Lys531-Asn791) from Pichia pastoris.

\section{Results}

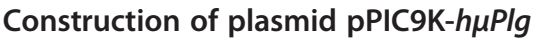

A full-length DNA sequence of the synthetic $h \mu P l g$ gene was inserted into the open reading frame of the $\alpha$-factor signal sequence of the $P$. pastoris expression vector pPIC9K, which is under the regulation of the $A O X 1$ promoter (Additional file 1). This plasmid was transformed into Escherichia coli DH5 $\alpha$ to express $\mathrm{h} \mu \mathrm{Plg}$. Enzyme digestion demonstrated that the $h \mu P l g$ gene was correctly oriented in the pPIC9K vector (Additional file 1). DNA sequencing of the recombinant vector confirmed the accuracy of the reading frame of $h \mu P l g$, and P. pastoris GS115 positive transformants were successfully identi-

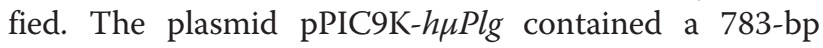
inserted target fragment. The deduced mature cDNA sequence of $r h \mu P l g$ encodes a 261-amion acid peptide with a theoretical MW of $28.63 \mathrm{kDa}$ and a $\mathrm{p} I$ of 7.95 .

\section{Transformation and screening of transformants}

After linearization with SalI, pPIC9K-h $\mu$ Plg was transformed into P. pastoris GS115 competent cells by electroporation. After an initial selection of His + transformants, clones were grown in microtiter plates until they reached the same optical density. The cultures were then spotted onto yeast extract-peptone-dextrose (YPD)-Geneticin plates (containing $2.0 \mathrm{mg} / \mathrm{mL}$ of Geneticin) and scored for Geneticin resistance. Five transformants, B2, B6, C3, F2, and F6, were obtained on the YPD-Geneticin plates. After genomic DNA was isolated from $P$. pastoris recombinants and controls, polymerase chain reaction (PCR) verification of the positive recombinants was performed using $5^{\prime}$ and 3' $A O X 1$ sequencing primers. Two bands were obtained

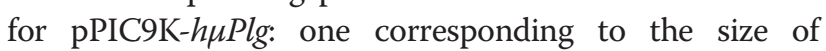
the $h \mu P l g$ gene plus the inserted $A O X 1$ gene in pPIC9K $(783+492 \mathrm{bp})$, and the other corresponding to the AOX1 gene in the chromosome of $P$. pastoris.

\section{Expression of rh $\mu \mathrm{Plg}$ in a shaker flask and a 5-L bioreactor}

The selected transformants (B2, B6, C3, F2, and F6) were cultured in a shaker flask to measure rh $\mu$ Plg expression. Maximum expression was observed after 4 days of methanol induction at $30{ }^{\circ} \mathrm{C}$. Supernatant proteins were subjected to sodium dodecyl sulfate-polyacrylamide gel electrophoresis (SDS-PAGE) analysis (Fig. 1, lanes 1-5). As shown in Fig. 1, a predominant band at approximately $35 \mathrm{kDa}$ was observed in lanes $1-5$. No target band was detected in the cultures of an induced transformant harboring an empty pPIC9K plasmid. GS115 F2 showed a distinctive band (lane 5), with a yield that reached $510.1 \mathrm{mg} / \mathrm{L}$ after $96 \mathrm{~h}$ of induction. Therefore, GS115 F2 was used for the subsequent expression of rh $\mu$ Plg.

As shown in Fig. 2a, fermentation was conducted in a 5-L bioreactor. The culture medium was collected and centrifuged every $5 \mathrm{~h}$ to obtain supernatants. Recombinant protein expression started $5 \mathrm{~h}$ after methanol induction and reached a peak at $40 \mathrm{~h}$ (Fig. 2a). At the end of the glycerol fed-batch phase, the biomass concentration reached $90 \mathrm{~g} / \mathrm{L}$. The methanol fed-batch phase of rh $\mu \mathrm{Plg}$ production lasted for $40 \mathrm{~h}$, and the final biomass 


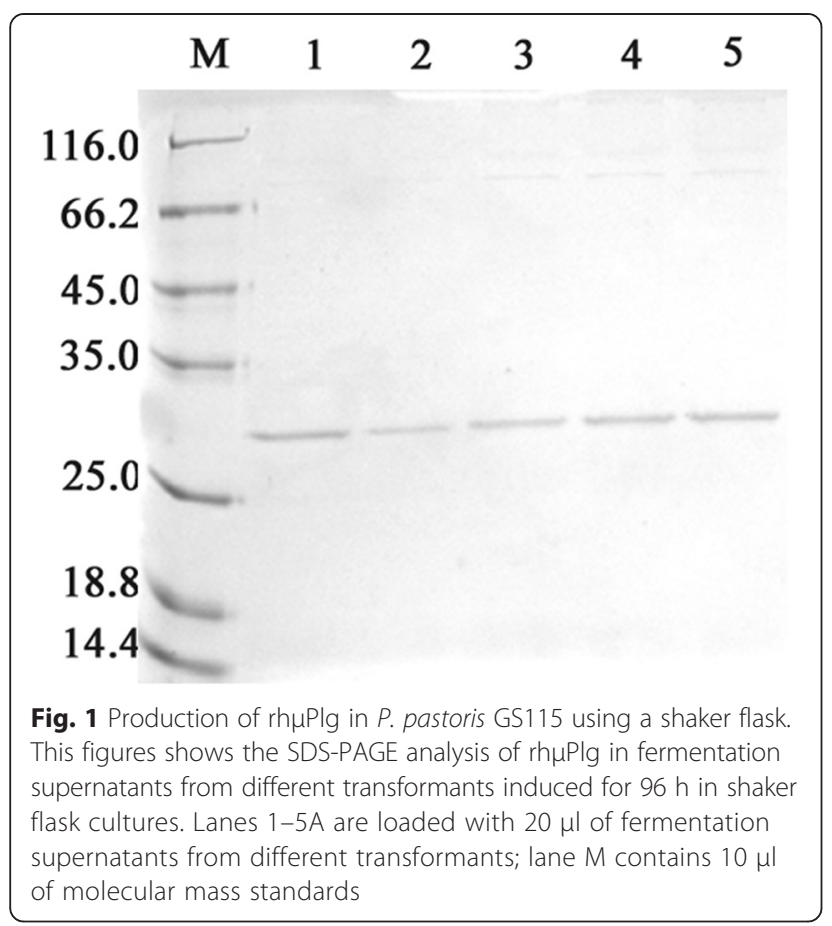

concentration reached $190 \mathrm{~g} / \mathrm{L}$, while the volume of the supernatant increased to $3.4 \mathrm{~L}$. After $40 \mathrm{~h}$ of induction, the total secreted protein concentration was $1.88 \mathrm{~g} / \mathrm{L}$, and the $\mathrm{rh} \mu \mathrm{Plg}$ activity in the supernatant reached 7.9 $\mathrm{U} / \mathrm{mL}$, which was 15 times that of the shaker flask fermentation.

\section{Purification of rh $\mu \mathrm{Plg}$}

The concentration of $\mathrm{rh} \mu \mathrm{Plg}$ in the bioreactor culture supernatant was estimated to be $1.0 \mathrm{~g} / \mathrm{L}$ based on SDSPAGE. The rh $\mu$ Plg expressed by $P$. pastoris was purified to homogeneity by ultrafiltration, followed by cation-exchange and Superdex 75 gel-filtration chromatography. The culture supernatant was collected and concentrated using membrane ultrafiltration. Subsequently, concentrated supernatant was loaded onto an SP Sepharose Fast Flow column, which bound most of the $\mathrm{rh} \mu \mathrm{Plg}$ (Fig. 2b). rh $\mu \mathrm{Plg}$ was eluted at $0.35 \mathrm{~mol} / \mathrm{L}$ in $\mathrm{NaCl}$-acetate buffer. $\mathrm{rh} \mu \mathrm{Plg}$ was further purified via high-resolution gel-filtration chromatography to remove trace impurities. Finally, we obtained $167 \mathrm{mg}$ of purified $\mathrm{rh} \mu \mathrm{Plg}$ per liter of culture supernatant (Additional file 2). The specific activity of purified $\mathrm{rh} \mu \mathrm{Plg}$ reached $23.6 \mathrm{U} / \mathrm{mg}$ protein (Additional file 2). The eluates containing $\mathrm{rh} \mu \mathrm{Plg}$ were analyzed using SDS-PAGE, followed by western blotting using a polyclonal antibody. The purity of rh $\mu \mathrm{Plg}$ reached $96 \%$, as determined by SDS-PAGE (Fig. 2b, lane 2).

\section{Characterization of $\mathrm{rh} \mu \mathrm{Plg}$}

$\mathrm{N}$-terminal sequencing indicated that the 10 amino acid residues at the $\mathrm{N}$-terminus of $\mathrm{rh} \mu \mathrm{Plg}$ were KLYDYCDVPQ, which matched the deduced amino acid sequence of mature $h \mu \mathrm{Plg}$. We determined that the secreted active protein contained 261 amino acids, which is consistent with the size of full-length $h \mu$ Plg.

\section{Mass spectrometry analysis}

An accurate mass can be detected by intact mass analysis using liquid chromatography-mass spectrometry (LC-MS). Peaks corresponding to various protonated rh $\mu \mathrm{Plg}$ species were determined. The mass analysis determined that $\mathrm{rh} \mu \mathrm{Plg}$ has a molecular weight of $28.55 \mathrm{kDa}$ (Fig. 3). This is identical to that identified by SDS-PAGE.

\section{Amidolytic assays and kinetic analysis}

Both plasmin and rh $\mu \mathrm{Plg}$ possess amidolytic activity against chromogenic substrates. The kinetic parameters $K_{m}, k_{c a t}$, and $k_{c a t} / K_{m}$ for such substrates are summarized
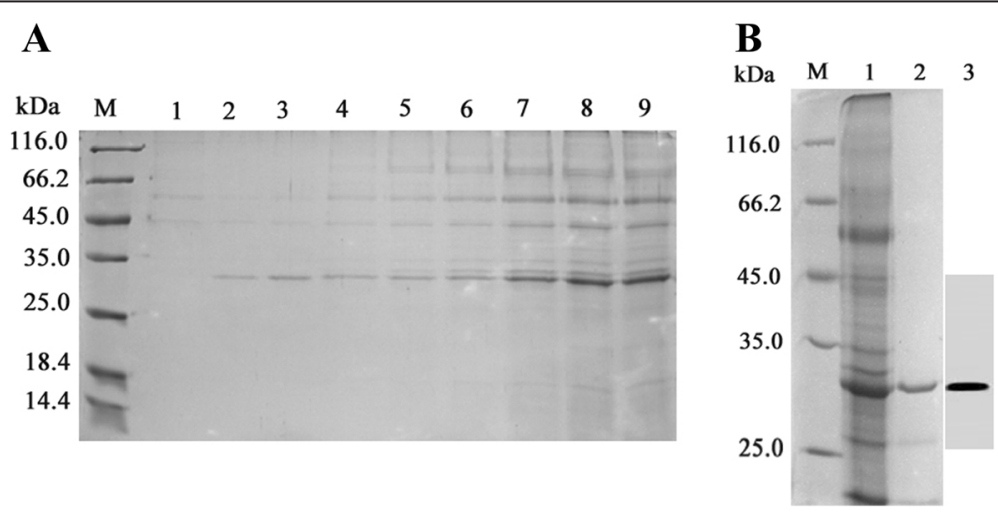

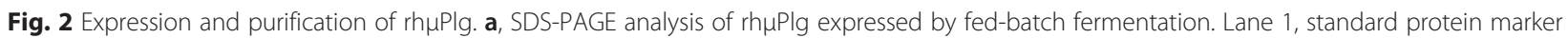
(14.4-116.0 kDa); Lane 1, uninduced P. pastoris; Lanes 2-9, P. pastoris induced with methanol for 5, 10, 15, 20, 25, 30, 35, and 40 h. b, M, standard protein marker. Lane 1, gel-filtration chromatography wash fraction; Lane 2, cation-exchange chromatography wash fraction 3; Lane 3, western blot of rhuPlg 


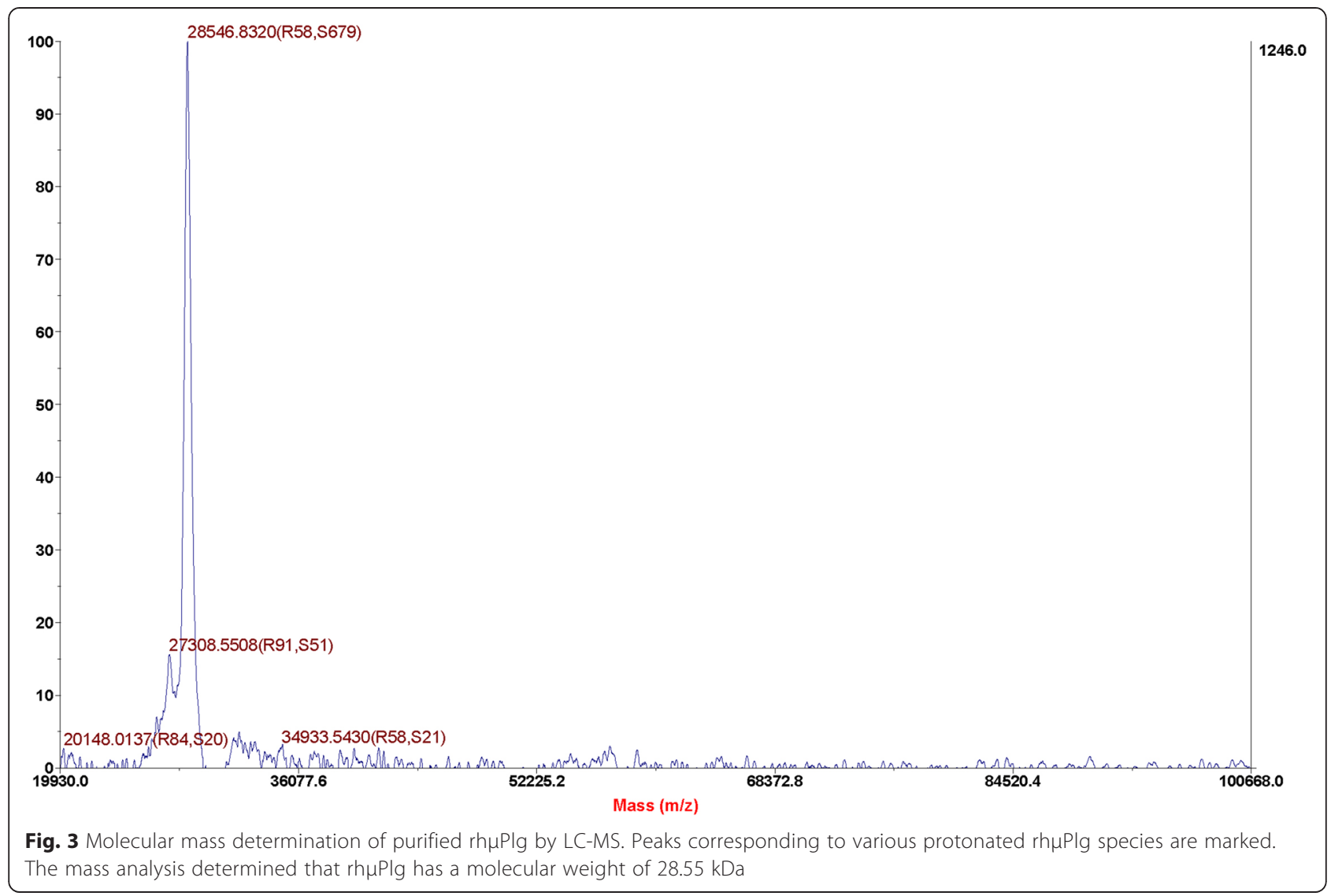

in Table 1 . The $K_{m}$ of substrate hydrolysis by rh $\mu$ Plg was comparable to that by human plasmin (Table 1 ), suggesting that kringle domains $1-5$ had no effect on the catalytic activity of plasmin. We also found that $r h \mu \mathrm{Plg}$ had higher $k_{\text {cat }} / K_{m}$ values than plasmin. The difference in the $k_{\text {cat }} / K_{m}$ values of the two proteinases was caused mainly by a variance in $k_{\text {cat }}$ (Table 1 ), which implied that there was a structural difference between the two proteins, probably owing to the closed conformation of plasmin. In addition, both serine proteases hydrolyzed a fibrin plate in a concentration-dependent manner, with slightly higher area values for rh $\mu$ Plg (Fig. 4).

\section{Discussion}

Plasminogen and its active form (plasmin) play important physiological and pathological roles in fibrinolysis and hemostasis, the degradation of the ECM, cell

Table 1 Kinetic parameters: comparison of plasminogen and rhuPlg

\begin{tabular}{llll}
\hline Enzyme & \multicolumn{3}{l}{ Amidase parameters } \\
\cline { 2 - 4 } species & $K_{m}(\mathrm{mM})$ & $k_{\text {cat }}\left(\mathrm{S}^{-1}\right)^{*}$ & $k_{\text {cat }} / K_{m}\left(\mathrm{mM}^{-1} \cdot \mathrm{S}^{-1}\right)^{*}$ \\
\hline Plasminogen & $0.325 \pm 0.016$ & $30.6 \pm 2.5$ & $94.15 \pm 0.03$ \\
rhuPlg & $0.348 \pm 0.021$ & $44.5 \pm 3.6$ & $127.87 \pm 0.01$ \\
\hline
\end{tabular}

Values given are means \pm SEM $(n=3) ;{ }^{*} P$ values $<0.05$ migration, tissue remodeling, wound healing, angiogenesis, inflammation, and tumor cell migration [15]. Consequently, patients with severe plasminogen deficiency typically suffer from a range of difficult to treat inflammatory conditions, including ligneous conjunctivitis, gingivitis, and neural disorders [16, 17]. Activation of the plasminogen system is tightly regulated, which is necessary to prevent the development of a systemic fibrinolytic state or tumor metastasis. The availability of rh $\mu \mathrm{Plg}$ with full enzymatic activity could be extremely valuable for structure-function studies of plasminogen and plasmin. In addition, its truncated derivative is also needed for various important therapeutic applications, including catheter-directed thrombolysis and treatment of acute ischemic stroke [18], acute lower extremity arterial or bypass graft occlusion [19], acute iliofemoral deep venous thrombosis [20] enzyme-induced vitreolysis, alleviating the progression of diabetic retinopathy [21], and treatment of diabetic retinopathy in young adults [22].

rh $\mu$ Plg has been expressed at high levels as inclusion bodies in E. coli [23, 24]. Recently, the methylotrophic yeast $P$. pastoris has been considered to be an excellent host for producing proteins obtained from different sources [25]. As a eukaryote, P. pastoris has many advantages. Proteins produced by $P$. pastoris are more likely to be processed, properly folded, and chemically 

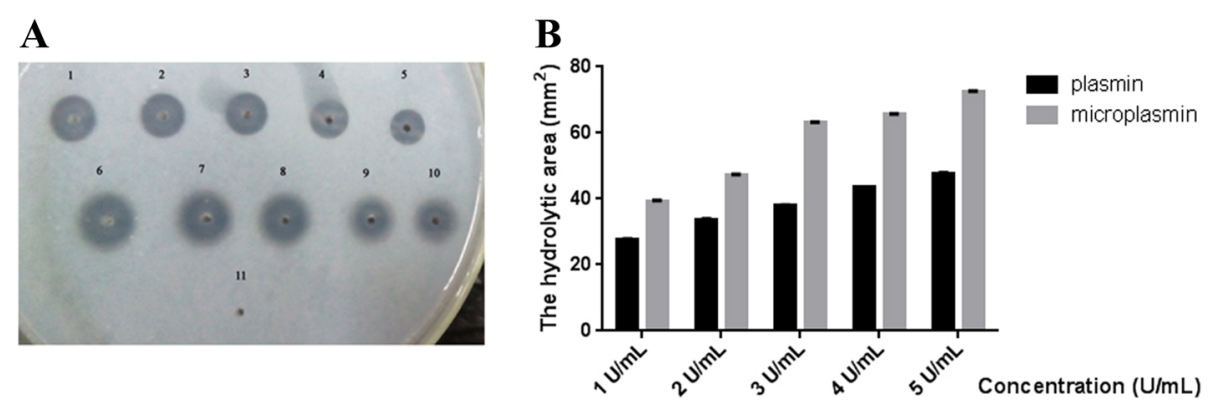

Fig. 4 Fibrinolytic activity of rhuPlg and plasminogen in a plasminogen-free fibrin agar plate. a, 1-5, plasmin with a concentration of 5, 4, 3, 2, and $1 \mathrm{U} / \mathrm{mL}$, respectively; 6-10, rhuPlg with a concentration of 5, 4, 3,2 and $1 \mathrm{U} / \mathrm{mL}$, respectively; 11, PBS as negative control. $\mathbf{b}$, Comparison of the fibrinolytic activity of plasmin and rhuPlg as calculated from the area of the lysis zone

modified. High expression levels, high cell densities in culture, easier upscaling, and strong and tightly regulated promoters have all been identified as advantages of using $P$. pastoris as a host [26]. In this study, rh $\mu$ Plg was expressed in $P$. pastoris, which was achieved by expressing $\mathrm{rh} \mu \mathrm{Plg}$ (comprising amino acids Lys531-Asn791), which lacks the five kringle domains. This method produced high yields $(1.88 \mathrm{~g} / \mathrm{L}$ of fermentation broth) of protein, which could be purified to homogeneity. The MW of rh $\mu$ Plg was different from that of the microplasmins produced by Nagai et al. and Joshi et al. [27, 28], both of which lacked $12 \mathrm{~N}$-terminal amino acids.

In this study, we cloned the cDNA gene of $h \mu P l g$ into a pPIC9K vector that contained an $\alpha$-factor secretion signal and allowed for the expression of $\mathrm{h} \mu \mathrm{Plg}$ in $P$. pastoris GS115. Transformants were selected based on their ability to grow on a medium lacking histidine, as well as on their Geneticin resistance. Enzymatically active rh $\mu$ Plg, which had a MW of $28.55 \mathrm{kDa}$, was expressed. Then, we developed a preparation of $r h \mu \mathrm{Plg}$ that was suitable for pharmaceutical use. The final, optimized process consists of a sequence of three chromatography steps. The first step (gel filtration) desalts and exchanges the buffer to acetate buffer, while the second step (cation exchange) captures rh $\mu \mathrm{Plg}$ and allows contaminants to flow through. A gel filtration/diafiltration step then serves to transfer the recombinant protein into its formulation buffer (20.0 mM phosphate buffer, $\mathrm{pH}$ 7.0). The final concentration was $1 \mathrm{mg} / \mathrm{ml}$ in phosphatebuffered saline ( $\mathrm{pH}$ 7.0). A preliminary characterization of rh $\mu \mathrm{Plg}$ was performed using western blotting, highperformance liquid chromatography, mass spectrometry, and N-terminal sequencing to verify the identity of the protein. We also completed a partial characterization of the functional properties of $\mathrm{rh} \mu \mathrm{Plg}$ by comparing its serine protease activity to that of commercially available plasmin. Our assays showed that when using an amidolytic chromophogenic substrate, the $K_{m}$ value of $r h \mu \mathrm{Plg}$ was similar to that of plasmin (Fig. 4). The catalytic efficiency, $k_{c a t} / K_{m}$, was higher for $r h \mu \mathrm{Plg}$ than plasmin. rh $\mu \mathrm{Plg}$, at a concentration similar to that of plasmin, exhibited a higher area value in the fibrinolysis plate, suggesting that kringle domains $1-5$ have no effect on the catalytic activity of plasmin.

The development of rh $\mu \mathrm{Plg}$ may solve most of the problems associated with the treatment of vitreoretinopathies with autologous plasmin. rh $\mu \mathrm{Plg}$ contains only the enzymatic portion of the plasmin molecule, while the other domains are omitted. This makes rh $\mu$ Plg much smaller than the original molecule $(28$ vs. $80 \mathrm{kDa}$, respectively) while retaining the same enzymatic activity, which theoretically would allow for greater penetration into epiretinal tissues. $\mathrm{rh} \mu \mathrm{Plg}$ has other advantages over plasmin. First, it is commercially available, allowing investigators to avoid the time-consuming and expensive steps necessary for the production of autologous plasmin enzyme. Second, it is generated by recombinant techniques, ensuring its sterility while avoiding the risk of microbial contamination. Last, it is inherently more stable than plasmin and can be stored in citrate buffer prior to use [29].

\section{Conclusions}

Our results demonstrate that high-purity rh $\mu$ Plg (Lys531Asn791) can be abundantly produced by $P$. pastoris. After purification and identification of rh $\mu \mathrm{Plg}$, we observed fibrinolytic activity in vitro, which suggested that $\mathrm{rh} \mu \mathrm{Plg}$ might play an active and beneficial role in treating thrombotic diseases and controlling the progression of vitreoretinopathies. Therefore, the possibility of producing rh $\mu \mathrm{Plg}$ for use in therapeutic applications could be fulfilled by $P$. pastoris. The successful expression of $\mathrm{rh} \mu \mathrm{Plg}$ in $P$. pastoris lays a solid foundation for its possible future applications.

\section{Methods}

Strains, vectors, reagents, and enzymes

The multi-copy Pichia expression kit containing P. pastoris strain GS115 and the pPIC9K vector were purchased from Invitrogen Corp. (Carlsbad, CA, USA). The 
E. coli strain DH5 $\alpha$ was purchased from Novagen (EMD Millipore, Billerica, MA, USA). E. coli cells containing plasmids were cultured aerobically at $37{ }^{\circ} \mathrm{C}$ in LuriaBertani medium (5 g/L yeast extract, $10 \mathrm{~g} / \mathrm{L}$ tryptone, $10 \mathrm{~g} / \mathrm{L} \mathrm{NaCl}$, and $15 \mathrm{~g} / \mathrm{L}$ agar) containing $100 \mu \mathrm{g} / \mathrm{ml}$ ampicillin to maintain the plasmids. Minimal dextrose (MD) medium, buffered complex glycerol medium (BMGY), YPD medium, buffered complex methanol medium (BMMY), and fermentation basal salts medium (BSM) supplemented with $\mathrm{PTM}_{1}$ solution $\left(0.2 \mathrm{~g} / \mathrm{L} \mathrm{H}_{3} \mathrm{BO}_{3}\right.$, $6.0 \mathrm{~g} / \mathrm{L} \mathrm{CuSO}_{4} 5 \mathrm{H}_{2} \mathrm{O}, 0.8 \mathrm{~g} / \mathrm{L} \mathrm{KI}, 3.0 \mathrm{~g} / \mathrm{L} \mathrm{MnSO}_{4} 2 \mathrm{H}_{2} \mathrm{O}$, $65 \mathrm{~g} / \mathrm{L} \quad \mathrm{FeSO}_{4} 7 \mathrm{H}_{2} \mathrm{O}, 0.2 \mathrm{~g} / \mathrm{L} \quad \mathrm{Na}_{2} \mathrm{MoO}_{4} 2 \mathrm{H}_{2} \mathrm{O}, 0.5 \mathrm{~g} / \mathrm{L}$ $\mathrm{CoCl}_{2}, \quad 20.0 \mathrm{~g} / \mathrm{L} \quad \mathrm{ZnCl}_{2}, \quad 5 \mathrm{~mL} / \mathrm{L} \quad \mathrm{H}_{2} \mathrm{SO}_{4}, \quad 0.5 \mathrm{~g} / \mathrm{L}$ $\mathrm{CaSO}_{4} \mathrm{H}_{2} \mathrm{O}$, and $0.2 \mathrm{~g} / \mathrm{L}$ biotin) were prepared according to Invitrogen's instructions for $P$. pastoris fermentation. Restriction enzymes and kits for cloning were obtained from New England Biolabs (Ipswich, MA, USA). The gene of interest, obtained from NCBI (GenBank: M74220.1, human plasminogen mRNA, complete coding sequence, nucleotides 1648-2430) was synthesized and cloned into plasmid pUC57 by Sangon Biological Co., Ltd. (Shanghai, China) (Additional file 3). The chromogenic substrate $\mathrm{H}$ D-Val-Phe-Lys-p-NA - 2HBr (S2390) was synthesized by the School of Pharmacy, Fudan University [30].

\section{Synthesis of the human $\mu \mathrm{Plg}$ gene and construction of the expression vector}

A DNA fragment was amplified by PCR using the synthetic gene as a template, which yielded an 814-bp product. The forward primer was 5' -CCGCTCGAGAAAAG AAAACTTTACGACTACTGTG (the underlined sequence is an XhoI site), and the reverse primer was $5^{\prime}$-AT AAGAATGCGGCCGCTTAATTATTTCTCATCACTCC (the underlined sequence is a NotI site). The total reaction volume was $20 \mu \mathrm{L}$, including $4 \mu \mathrm{L}$ of $5 \times$ Phusion HF DNA polymerase, $0.4 \mu \mathrm{L}$ of $10 \mathrm{mM}$ dNTPs, $1.0 \mu \mathrm{L}$ of the forward primer $(10 \mathrm{mM}), 1.0 \mu \mathrm{L}$ of the reverse primer (10 mM), $0.25 \mu \mathrm{L}$ of Phusion DNA polymerase, $12.35 \mu \mathrm{L}$ of sterile water, and $1 \mu \mathrm{L}$ of pUC57- $\mu \mathrm{Plg}(10 \mathrm{ng} / \mu \mathrm{L})$. Amplification conditions were $30 \mathrm{~s}$ at $98{ }^{\circ} \mathrm{C}, 30$ cycles of $10 \mathrm{~s}$ at $98{ }^{\circ} \mathrm{C}, 20 \mathrm{~s}$ at $49{ }^{\circ} \mathrm{C}$, and $30 \mathrm{~s}$ at $72{ }^{\circ} \mathrm{C}$, followed by a final extension of $5 \mathrm{~min}$ at $72{ }^{\circ} \mathrm{C}$. The PCR product was ligated into the $\mathrm{PPIC} 9 \mathrm{~K}$ vector between the XhoI and NotI sites. The recombinant plasmid was transformed into E. coli JM109, and transformants were identified by restriction digest analysis and sequencing. The theoretical MW and $\mathrm{p} I$ were calculated using the website http://web.expasy.org/compute_pi/.

\section{Transformation and screening of multi-copy transformants}

SalI was used to linearize $10 \mu \mathrm{g}$ of the pPIC9K- $h \mu P l g$ plasmid, and the linear DNA was then transformed into P. pastoris GS115 cells using a GenePulser system
(Bio-Rad, Carlsbad, CA, USA) under the following conditions: $1.5 \mathrm{kV}, 200 \Omega$, and $25 \mu \mathrm{F}$ ). His + transformants were selected on YPD plates containing Geneticin 418 (2-6 $\mathrm{mg} / \mathrm{ml})$, and then lysed by a combined enzyme, freezing, and heating treatment according to a simple protocol reported in the literature [31]. The cell lysate containing the genomic DNA was analyzed by PCR using the 5'AOX1 primer 5'-GACTGGTTCCAATTGACAAGC-3' and the $3^{\prime} A O X 1$ primer 5'-GCAAATGGCATTCTGACA TCC-3'. The total reaction volume was $50 \mu \mathrm{L}$, including $5 \mu \mathrm{L}$ of $10 \times$ reaction buffer, $5 \mu \mathrm{L}$ of $25 \mathrm{mM} \mathrm{MgCl}_{2}, 1 \mu \mathrm{L}$ of $25 \mathrm{mM}$ dNTPs, $1 \mu \mathrm{L}$ of the $5^{\prime} A O X 1$ primer $(10 \mathrm{pmol} / \mu \mathrm{L})$, $1 \mu \mathrm{L}$ of the $3^{\prime} A O X 1$ primer $(10 \mathrm{pmol} / \mu \mathrm{L}), 27 \mu \mathrm{L}$ of sterile water, and $5 \mu \mathrm{L}$ of cell lysate. The reaction was incubated in a thermocycler at $95{ }^{\circ} \mathrm{C}$ for $5 \mathrm{~min}$, and $5 \mu \mathrm{l}$ of a $0.16 \mathrm{U} / \mu \mathrm{l}$ solution of $\mathrm{Taq}$ polymerase ( 0.8 units) was added. The amplification conditions were 30 cycles of $1 \mathrm{~min}$ at $95{ }^{\circ} \mathrm{C}$, $1 \mathrm{~min}$ at $54{ }^{\circ} \mathrm{C}$ and $1 \mathrm{~min}$ at $72{ }^{\circ} \mathrm{C}$, followed by a final extension of $7 \mathrm{~min}$ at $72{ }^{\circ} \mathrm{C}$.

\section{Production of rh $\mu \mathrm{Plg}$ in a shaking flask and a 5-L bioreactor} The colonies of His + transformants exhibiting resistance to $2.0 \mathrm{mg} / \mathrm{ml}$ Geneticin were inoculated in $10 \mathrm{ml}$ of BMGY (2 \% peptone, $1 \%$ yeast extract, $100 \mathrm{mM}$ potassium phosphate, $\mathrm{pH} 6.0,1.34 \%$ yeast nitrogen base (without amino acids), $0.4 \mu \mathrm{g} / \mathrm{ml}$ biotin, and $1 \%$ glycerol) at $30{ }^{\circ} \mathrm{C}$ with constant shaking at $250 \mathrm{rpm}$ until the $\mathrm{OD}_{600}$ was 4 . To accurately measure $\mathrm{OD}_{600}>1.0$, a sample of the culture was diluted 10 -fold before reading. The cells were then resuspended in $10 \mathrm{ml}$ of BMMY (2\% peptone, $1 \%$ yeast extract, $100 \mathrm{mM}$ potassium phosphate, $\mathrm{pH}$ 6.0, $1.34 \%$ yeast nitrogen base (without amino acids), $0.4 \mu \mathrm{g} / \mathrm{ml}$ biotin, and $0.5 \%$ methanol), and expression was induced at $30{ }^{\circ} \mathrm{C}$ with constant shaking at $250 \mathrm{rpm}$ for $96 \mathrm{~h}$. Methanol was added at a concentration of $1 \%(\mathrm{v} / \mathrm{v})$ every $24 \mathrm{~h}$. The supernatant was collected for activity assays and SDS-PAGE analysis.

The inoculum seeds of $P$. pastoris were cultured at $30{ }^{\circ} \mathrm{C}$ on a shaker at $250 \mathrm{rpm}$ for $24 \mathrm{~h}$ in $200 \mathrm{ml}$ of YPD medium. A total of $200 \mathrm{ml}$ of the seed broth was inoculated into a 5-L fermenter (Bioflo 3000 fermenter, New Brunswick Scientific, New Brunswick, NJ, USA) containing $3 \mathrm{~L}$ of BSM plus $2 \mathrm{ml} / \mathrm{L}$ of $\mathrm{PTM}_{1}$ solution. The $\mathrm{pH}$ of the medium was adjusted to and maintained at 5.0 via the addition of ammonium hydroxide. The temperature was maintained at $30{ }^{\circ} \mathrm{C}$, and the dissolved oxygen level was maintained at over $35 \%$ of air saturation by a cascaded control of agitation speed and aeration rate. After glycerol exhaustion, $200 \mathrm{ml}$ of feeding medium containing $50 \%(\mathrm{w} / \mathrm{v})$ glycerol and $2 \mathrm{ml} / \mathrm{L}$ of $\mathrm{PTM}_{1}$ solution were pumped into the bioreactor according to Invitrogen's instructions for P. pastoris fermentation. After the depletion of glycerol, pure methanol containing $2 \mathrm{ml} / \mathrm{L}$ of $\mathrm{PTM}_{1}$ was added to the bioreactor. The production 
phase lasted $40 \mathrm{~h}$ at $30{ }^{\circ} \mathrm{C}$, with a gradual increase in the methanol feeding rate from 0.8 to $4 \mathrm{ml} / \mathrm{L} . \mathrm{h}$, which allowed the culture to adapt to the methanol. After $6 \mathrm{~h}$, the methanol feed rate was maintained at $4 \mathrm{ml} / \mathrm{L} / \mathrm{h}$ for an additional $34 \mathrm{~h}$. Samples were collected for the determination of the $\mathrm{OD}_{600}$, dry cell weight, fibrinolytic activity, and protein concentration.

\section{Purification of rh $\mu \mathrm{Plg}$}

The culture was centrifuged and the supernatant was ultrafiltered, followed by gel-filtration and cationexchange chromatography. The concentrated supernatant was loaded onto a Sephadex G-50 column $(7.5 \mathrm{~cm} \times 100 \mathrm{~cm})$ that was already equilibrated with $20 \mathrm{mmol} / \mathrm{L}$ acetate buffer (pH 5.0). One thousand milliliters of collected sample, which was eluted from the gel-filtration column, was loaded onto a SP-Sepharose FF column $(2.6 \mathrm{~cm} \times 20 \mathrm{~cm})$, which was also equilibrated with $20 \mathrm{mmol} / \mathrm{L}$ acetate buffer ( $\mathrm{pH} \mathrm{5.0)}$ ). It was washed with $20 \mathrm{mmol} / \mathrm{L}$ acetate buffer $(\mathrm{pH} 5.0)$, followed by a single linear gradient of $0-1.0 \mathrm{~mol} / \mathrm{L}$ $\mathrm{NaCl}$-acetate buffer. The fractions were collected for activity assays and SDS-PAGE analysis, then desalted with a Superdex 75 column $(5.0 \mathrm{~cm} \times 100 \mathrm{~cm})$. Forty milliliters of sample was loaded each time. The desalted sample was lyophilized and stored at $-80^{\circ} \mathrm{C}$.

\section{Western blotting}

Proteins resolved by SDS-PAGE were electrotransferred to a polyvinylidene fluoride membrane followed by blocking in $5 \%$ skim milk prepared in Tris-buffered saline containing $0.05 \%$ Tween-20 (TBST). The membrane was then incubated with an anti-rh $\mu$ Plg polyclonal antibody (1:1000 dilution) (16776-1-AP, Proteintech Group, Chicago, IL, USA) for $90 \mathrm{~min}$ at room temperature. After washing, the membrane was incubated with a horseradish peroxidase-conjugated goat anti-rabbit IgG (1:10,000 dilution) (CW0103, Cwbiotech, Beijing, China) for $60 \mathrm{~min}$ at room temperature. All antibody incubations and washing steps were conducted in TBST. Immunoreactive bands were visualized with an enhanced chemiluminescent substrate (PA109, Tiangen Biotech, Beijing, China).

\section{Mass spectrometry analysis}

The purified protein was analyzed by mass spectrometry. Molecular weight measurements were made by matrixassisted laser desorption-ionization time of flight mass spectrometry (AB SCIEX) at the Shanghai Applied Protein Technology Co., Ltd.

\section{Amidolytic assays and kinetic analysis}

Amidolytic activity was measured using H-D-Val-Phe-Lys$\mathrm{p}-\mathrm{NA} \cdot 2 \mathrm{HBr}$, a chromogenic substrate containing a $\rho$ nitroanilide ( $\rho$-NA) group [32]. Human plasminogen was used as a standard to calculate the activity units of rh $\mu \mathrm{Plg}$. Fifty microliters of substrate $(1.25 \mathrm{mM})$ was added to $50-\mu \mathrm{l}$ solutions of various concentrations of proteinases in $50 \mathrm{mM}$ Tris- $\mathrm{HCl}, \mathrm{pH}$ 7.4. The release of $\rho-\mathrm{NA}$ was then monitored continuously at $405 \mathrm{~nm}$. The amount of substrate hydrolyzed was calculated from the increase in absorbance at $405 \mathrm{~nm}$, using a molar extinction coefficient of $10,000 \mathrm{M}^{-1} \cdot \mathrm{cm}^{-1}$ for free $\rho$-NA. One unit of enzyme will produce one umole of $\rho$-nitroanilide from H-D-Val-PheLys-p-NA $2 \mathrm{HBr}$ per minute at $37{ }^{\circ} \mathrm{C}, \mathrm{pH}$ 7.4 (Amidase unit). The Michaelis constant $\left(K_{m}\right)$ and catalytic rate constant $\left(k_{c a t}\right)$ were determined from Lineweaver-Burk plots.

\section{Enzyme assays and protein analysis}

The catalytic activity of rh $\mu \mathrm{Plg}$ was assayed and compared with that of plasminogen. Fibrinolysis was performed on a fibrin plate, as described by Choi and Sa [33]. Briefly, a mixture of $0.6 \%(\mathrm{w} / \mathrm{v})$ fibrinogen and $2 \%(\mathrm{w} / \mathrm{v})$ agar was prepared in $50 \mathrm{mM}$ sodium phosphate buffer at $\mathrm{pH} 7.4$, boiled for $2 \mathrm{~min}$, cooled to $55^{\circ} \mathrm{C}$, and subsequently mixed with thrombin $\left(10 \mathrm{NIH}\right.$ units $\left.\mathrm{ml}^{-1}\right)$ for coagulation in a Petri dish. Serial dilutions of the enzyme solution $(1,2,3$, 4 , and $5 \mathrm{U} / \mathrm{mL}$ ) were prepared in $50 \mathrm{mM}$ sodium phosphate buffer, and approximately $15 \mu \mathrm{l}$ was injected into sample pools in the fibrin plate and incubated at $37{ }^{\circ} \mathrm{C}$ for $18 \mathrm{~h}$. The product of the diameters of two perpendicular lysis zones was used as the measure of fibrinolytic activity. The areas of the zones hydrolyzed by the same concentration of protease were compared.

Total protein concentrations were determined by the BCA assay kit (Thermo Fisher Scientific, Waltham, MA, USA) using bovine serum albumin as a standard. Proteins were analyzed on $12 \%$ polyacrylamide gels under denaturing conditions. BandScan, a software to detect protein or nucleic acid quantity by gray scanning, was used for analysis of protein expressed level under different conditions [34]. The target protein concentration was determined by scanning a stained SDS-PAGE with BandScan software. Gray scanning analysis by BandScan software showed that the target protein under different concentrations accounted for the percent of the total protein. Then the target protein concentration can be caculated. N-terminal sequencing was performed by Shanghai Genecore Biotechnologies (Shanghai, China).

\section{Additional files}

Additional file 1: Cloning and schematic representation of $h \mu \mathrm{Plg}$

cloning. Figure (A) represents cloning of huPlg from plasmid pUC57 to pPIC9K vector. $M$ - DNA Marker, 1- PCR with gene specific primers using pUC57 as template, 2- restriction digestion of pPIC9K-huPlg with Xhol and

Sall, 3- restriction digestion of PPIC9K-hMPlg with Notl and Sall,

4- restriction digestion of pPIC9K-huPlg with Rsrll. Figure (B) represents the schematic diagrams of pPIC9K-huPlg

Additional file 2: Summary of the purification of rhuPlg. 
Additional file 3: Nucleotide sequence and corresponding amino acid sequence of $h \mu \mathrm{Plg}$. The mature CDNA sequence of rhuPlg encodes a 261-amion acid peptide.

\section{Abbreviations}

huPlg: Human microplasminogen; rhuPlg: Recombinant human microplasminogen; rhuPIm: Recombinant human microplasmin; tPA: Tissue plasminogen activator; AOX: Alcohol oxidase; uPA: urokinase plasminogen activator; SP: Serine protease; ECM: Extracellular matrix; MD: Minimal dextrose; YPD: Yeast extract-peptone-dextrose; BMGY: Buffered complex glycerol medium; BMMY: Buffered complex methanol medium; BSM: Basal salts medium; MW: Molecular weight; TBST: Tris-buffered saline containing $0.05 \%$ Tween-20; $\rho$-NA: $\rho$-nitroanilide; Km: Michaelis constant; kcat: Catalytic rate constant; SDS-PAGE: Sodium dodecyl-sulfate polyacrylamide gel electrophoresis.

\section{Competing interests}

The authors declare that they have no competing interests.

\section{Authors' contributions}

$R L, B Z$, and $Y Z$ performed the protein expression and purification. JG and MRY analyzed the protein activity. RL and WM designed the experiments, analyzed data, and wrote the paper. MY supervised the experiments. HS is the first inventor of rhuPlg. All authors read and approved the final manuscript.

\section{Acknowledgments}

This study was supported by the National Natural Science Foundation of China (NSFC 21242009, NSFCJ121041, JYH6273102/007/016/007) and the Science and Technology Commission of Shanghai Municipality (STCSM $10431901000 \& 14431900100)$. This study was also supported by the State Key Laboratory of Biotherapy/Collaborative Innovation Center for Biotherapy, West China Hospital, Sichuan University.

\section{Author details}

${ }^{1}$ Key Laboratory of Metabolism and Molecular Medicine, Ministry of Education, Fudan University, 138 Yixueyan Rd, Shanghai 200032, China. ${ }^{2}$ Department of Biochemistry and Molecular Biology, School of Basic Medical Sciences, Fudan University, 138 Yixueyan Rd, Shanghai 200032, China. ${ }^{3}$ Collaborative Innovation Center for Biotherapy, Sichuan University, Huaxi Campus: No.17 People's South Road, Chengdu 610041, China.

\section{Received: 4 February 2015 Accepted: 1 June 2015}

\section{Published online: 09 June 2015}

\section{References}

1. Petersen TE, Martzen MR, Ichinose A, Davie EW. Characterization of the gene for human plasminogen, a key proenzyme in the fibrinolytic system. J Biol Chem. 1990;265:6104-11.

2. Raum D, Marcus D, Alper C, Levey R, Taylor P, Starzl T. Synthesis of human plasminogen by the liver. Science. 1980;208:1036-7.

3. Zhang L, Seiffert D, Fowler BJ, Jenkins GR, Thinnes TC, Loskutoff DJ, et al. Plasminogen has a broad extrahepatic distribution. Thromb Haemost. 2002;87:493-501.

4. Law Ruby HP, Caradoc-Davies T, Cowieson N, Horvath Anita J, Quek Adam J, Encarnacao Joanna A, et al. The X-ray crystal structure of full-length human plasminogen. Cell Reports. 2012;1:185-90.

5. Wu HL, Shi GY, Bender ML. Preparation and purification of microplasmin. Proc Natl Acad Sci U S A. 1987;84:8292-5.

6. Wu HL, Shi GY, Wohl RC, Bender ML. Structure and formation of microplasmin. Proc Natl Acad Sci U S A. 1987;84:8793-5.

7. Novokhatny $\vee$. Structure and activity of plasmin and other direct thrombolytic agents. Thromb Res. 2008;122:S3-8.

8. Alkjaersig N, Fletcher AP, Sherry S. The mechanism of clot dissolution by plasmin. J Clin Invest. 1959;38:1086-95.

9. Marder VJ. Historical perspective and future direction of thrombolysis research: the re-discovery of plasmin. J Thromb Haemost. 2011;9:364-73.

10. Wu WC, Liu CH, Chen CC, Wang NK, Chen KJ, Chen TL, et al. Efficient vitreolysis by combining plasmin and sulfur hexafluoride injection in a preclinical study in rabbit eyes. Mol Vis. 2012;18:2361-70.
11. Elbendary AM, Elwan MM, Azzam HA, Eldeeb DR. Predictability of vitreous detachment following intravitreal plasmin injection in diabetic macular edema associated with vitreomacular traction. Curr Eye Res. 2011;36:534-9.

12. Gandorfer A, Putz E, Welge-Lussen U, Gruterich M, Ulbig M, Kampik A. Ultrastructure of the vitreoretinal interface following plasmin assisted vitrectomy. Br J Ophthalmol. 2001;85:6-10.

13. Gandorfer A, Priglinger S, Schebitz K, Hoops J, Ulbig M, Ruckhofer J, et al. Vitreoretinal morphology of plasmin-treated human eyes. Am J Ophthalmol. 2002;133:156-9.

14. El-Asrar AM, Al-Mezain HS. Pharmacologic vitreolysis in diabetic retinopathy. Curr Pharm Biotechnol. 2011;12:406-9.

15. Miles LA, Parmer RJ. Plasminogen receptors: the first quarter century. Semin Thromb Hemost. 2013;39:329-37.

16. Mehta R, Shapiro AD. Plasminogen deficiency. Haemophilia. 2008;14:1261-8.

17. Schuster $V$, HÜGle B, Tefs K. Plasminogen deficiency. J Thromb Haemost. 2007;5:2315-22.

18. Balami JS, Chen R, Sutherland BA, Buchan AM. Thrombolytic agents for acute ischaemic stroke treatment: the past, present and future. CNS Neurol Disord Drug Targets. 2013;12:145-54.

19. Marder VJ, Comerota AJ, Shlansky-Goldberg RD, Davis JP, Deng C, Hanna K, et al. Safety of catheter-delivered plasmin in patients with acute lower extremity arterial or bypass graft occlusion: phase I results. J Thromb Haemost. 2012;10:985-91.

20. Liu F, Lu P, Jin B. Catheter-directed thrombolysis for acute iliofemoral deep venous thrombosis. Ann Vasc Surg. 2011;25:707-15.

21. Li C, Chen P, Zhang J, Zhang L, Huang X, Yao Y, et al. Enzyme-induced vitreolysis can alleviate the progression of diabetic retinopathy through the HIF-1a pathway. Invest Ophthalmol Vis Sci. 2013;54:4964-70.

22. Raczynska D, Zorena K, Urban B, Zalewski D, Skorek A, Malukiewicz G, et al. Current trends in the monitoring and treatment of diabetic retinopathy in young adults. Mediators Inflamm. 2014. doi:10.1155/2014/492926.

23. Ma Z, Lu W, Wu S, Chen J, Sun Z, Liu J-N. Expression and characterization of recombinant human micro-plasminogen. Biotechnol Lett. 2007;29:517-23.

24. Medynski D, Tuan M, Liu W, Wu S, Lin X. Refolding, purification, and activation of miniplasminogen and microplasminogen isolated from E. coli inclusion bodies. Protein Expr Purif. 2007;52:395-402.

25. Macauley-Patrick S, Fazenda ML, McNeil B, Harvey LM. Heterologous protein production using the Pichia pastoris expression system. Yeast. 2005;22:249-70.

26. Cregg JM, Tolstorukov I, Kusari A, Sunga J, Madden K, Chappell T. Expression in the yeast Pichia pastoris. In: Richard RB, Murray PD, editors. Methods Enzymol. New York: Academic; 2009. p. 169-89.

27. Nagai N, Demarsin E, Van Hoef B, Wouters S, Cingolani D, Laroche Y, et al. Recombinant human microplasmin: production and potential therapeutic properties. J Thromb Haemost. 2003;1:307-13.

28. Joshi KK, Sahni G. Molecular cloning, expression, purification and characterization of truncated forms of human plasminogen in Pichia pastoris expression system. Process Biochem. 2010;45:1251-60.

29. Schneider EW, Johnson MW. Emerging nonsurgical methods for the treatment of vitreomacular adhesion: a review. Clin Ophthalmol. 2011;5:1151-65.

30. Chi C, Zhu C. The synthesis of plasmin substrates S2390. Acta Acad Med Shanghai. 1990;17:175-6.

31. Linder S, Schliwa M, Kube-Granderath E. Direct PCR screening of Pichia pastoris clones. Biotechniques. 1996;20:980-2.

32. Zhu Z, Liang Z, Zhang T, Zhu Z, Xu W, Teng M, et al. Crystal structures and amidolytic activities of two glycosylated snake venom serine proteinases. J Biol Chem. 2005;280:10524-9.

33. Choi HS, Sa YS. Fibrinolytic and antithrombotic protease from Spirodela polyrhiza. Biosci Biotechnol Biochem. 2001;65:781-6.

34. Pan Z, Xu L, Zhu Y, Shi H, Chen Z, Chen M, et al. Characterization of a new cry $2 \mathrm{Ab}$ gene of Bacillus thuringiensis with high insecticidal activity against Plutella xylostella L. World J Microbiol Biotechnol. 2014;30:2655-62. 